\title{
Sombras de violência: premissas ocultas em epistemologias
}

\section{Shadows of violence: premises hidden in epistemologies}

\section{Sombras de violencia: premisas ocultas en epistemologías}

\author{
Roque Strieder \\ Universidade do Oeste de Santa Catarina de Joaçaba, Professor e Pesquisador no Programa \\ de Mestrado em Educação \\ Clenio Lago ${ }^{2}$ \\ Universidade do Oeste de Santa Catarina de Joaçaba, Professor e Pesquisador no Programa \\ de Mestrado em Educação
}

Resumo: Existe algo desconcertante na trajetória humana, pois mesmo desejando o bem e a felicidade, toleramos e conservamos atitudes de violência. Historicamente a violência gerou graus significativos de dor e sofrimento. Em sua breve história, o ser humano foi e é capaz das mais terríveis atrocidades e deixa expresso, nessa história, um rastro indelével de maldade e sofrimento. $\bigcirc$ ser humano contemporâneo, no seio da civilização, vive cercado de ambiguidades, paradoxos e desigualdades que expressam e renovam formas de violência. Reencontramo-nos com horrores, angústias e desesperanças de antes e as elasticamos para o amanhã. Diante desses cenários, radicados em violências de múltiplos matizes, o horizonte do trabalho é lançar luzes refletindo sobre a epistemologia em meio às emergências de diferentes emocionalidades e racionalidades. Assim, diante das inflexões da complexidade da condição humana, perguntamos: como violência e epistemologia estão articuladas e como uma dimensão epistemológica pode constituir-se para além de ser expressão violenta e da violência? Acenam-se com diferentes possibilidades de refletir, discutir e lidar com uma das inglórias faces da dimensão humana: a capacidade de exercitar e exercitar-se em violência no âmbito do conhecer. Concluímos que a profanação das epistemologias que fazem pervagar violências, para restaurar um ser humano qualquer, sem essência ou destino

Doutor em Educação pela Universidade Metodista de Piracicaba; Mestre em Educação pela Universidade Federal de Santa Catarina.

2 Doutor em Educação pela Pontifícia Universidade Católica do Rio Grande do Sul; Mestre em Educação pela Universidade Federal de Santa Maria. 
a galgar, numa comunidade que vem, vacilante entre a singularidade e o universal, é uma tarefa da formação que vem, ancorada em um conhecer para além da fragmentação e dos mecanismos sistemáticos.

Palavras-chave: Educação. Epistemologia. Violência. Experiências formativas.

Abstract: There is something disconcerting in the human trajectory, for even wishing good and happiness, we tolerate and preserve attitudes of violence. Historically violence has generated significant degrees of pain and suffering. The contemporary human, within civilization, lives surrounded by ambiguities, paradoxes and inequalities, which express and renew forms of violence. We meet again with horrors, anguish, and hopelessness from before, and stretch them to tomorrow. Faced with these scenarios, rooted in violence of multiple shades, the horizon of work is to shed light reflecting on epistemology amid the emergencies of different emotionalities and rationalities. Thus, into the inflections of the complexity of the human condition, we ask: how are violence and epistemology articulated and how can an epistemological dimension be constituted beyond being violent expression and violence? Different possibilities are presented to reflect, discuss and deal with one of the inglorious faces of the human dimension: the capacity to exercise and to exercise in violence in the scope of knowing. We conclude that the desecration of epistemologies that pervade violence, to restore any human being, without essence or destiny to rise, in a community that comes, hesitating between the singularity and the universal is a task of formation that comes, anchored in a knowing beyond fragmentation and systematic mechanisms.

Keywords: Education. Epistemology. Violence. Formative experiences.

Resumen: Hay algo desconcertante en la trayectoria humana, pues aun deseando el bien y la felicidad, toleramos y conservamos actitudes de violencia. Históricamente la violencia generó grados significativos de dolor y sufrimiento. En su breve historia, el ser humano ha sido y es capaz de las más terribles atrocidades y deja expresado, en esa historia, un rastro indeleble de maldad y sufrimiento. El ser humano contemporáneo, en el seno de la civilización vive rodeado de ambigüedades, paradojas y desigualdades, que expresan y renuevan formas de violencia. Nos reencuentramos con horrores, angustias y desesperanzas de antes y las elasticamos para el mañana. Ante estos escenarios, radicados en violencias de múltiples matices, el horizonte del 
trabajo es lanzar luces reflexionando sobre la epistemología en medio de las emergencias de diferentes emociones y racionalidades. Así, en medio de las inflexiones de la complejidad de la condición humana preguntamos: ¿cómo se articulan la violencia y la epistemología y cómo una dimensión epistemológica puede constituirse más allá de ser expresión violenta y de la violencia? Se acentúan con diferentes posibilidades de reflexionar, de discutir y lidiar con una de las caras de la dimensión humana: la capacidad de ejercitar y ejercitarse en violencia en el ámbito del conocimiento. Concluimos que la profanación de las epistemologías que hacen pervivar violencias, para restaurar a un ser humano cualquiera, sin esencia o destino a galgar, en una comunidad que viene, vacilante entre la singularidad y lo universal, es una tarea de la formación que viene, anclada en un conocer para además de la fragmentación y los mecanismos sistemáticos.

Palabras clave: Educación. Epistemología. Violencia. Experiencias formativas.

\section{CONSIDERAÇÕES INICIAIS}

Violência é um tema multifacetado que acolhe posições das mais brandas às mais extremas. Os estudos, as reflexões e os debates, na contemporaneidade, sobre a violência precisam considerar a sua radicalidade, como um conteúdo que acompanha a humanidade desde o princípio, que vem do fundo dos tempos. Requer revisitar os registros mitológicos - tragédias gregas, Caixa de Pandora, deuses, heróis, monstros, etc. -; observá-la nas vertentes e nas raízes religiosas - como as cruzadas, que se banharam no sangue dos mouros, o genocídio de tribos indígenas, as fogueiras queimando hereges, católicos e protestantes digladiando-se na Irlanda do Norte, as divergências religiosas na Bósnia -; e sem negligenciar as lógicas instrumentais da modernidade - tecnologias das guerras, campos de concentração, terror, etc., todas como tentativas de visualizar atividades simbólicas da violência, que sofre mutações e mostra diferentes rostos em cada tempo e em cada cultura.

Historicamente o emprego da violência tem gerado um grau significativo de dor e sofrimento a grupamentos humanos. Em sua breve história, o ser humano foi e é capaz das mais terríveis atrocidades e deixa expresso, 
nessa história, um rastro indelével de maldade e sofrimento, contrários à paz e a justiça. Existe algo de desconcertante na existência da humanidade, pois mesmo desejando o bem e a felicidade, ela vivencia, tolera, conserva e reinventa atitudes de violência.

Dos homínidas aos humanos, nos humanos em suas múltiplas organizações violamos a vida e a condição humana. Homicídios, abortos, genocídios, etnocídios e o suicídio individual são recorrentes. Fomos criadores e aperfeiçoamos as técnicas de violar a integridade física da pessoa humana pelas mutilações, pelas torturas, pelas prisões arbitrárias, a escravidão, a prostituição, o comércio de pessoas, o comércio de órgãos, até as condições degradantes do trabalho na forma emprego pela precarização, pelo trabalho multifuncional, entre outros (ANTUNES, 2006). ${ }^{3}$ Além da violência física, esta também se expressa de forma difusa por meio da repreensão diante das escolhas, da obrigatoriedade do cumprimento de horários, da violência das urgências no "temos que agir agora", da radicalidade das metas a cumprir, da vigilância e controle sobre os gestos e os ritmos, da diversidade de dispositivos ${ }^{4}$ sobre as condições de trabalho/emprego, bem como da lógica conquistadora, prática recorrente do autoritarismo e das democracias e demais estruturas de poder equivocadas.

Todas as vezes que tentamos perscrutar a temática da violência, ela nos escapa e desembocamos em algo misterioso, uma vez que o emprego da força, de forma sistemática ou como possibilidade na resolução dos conflitos de ordem individual ou grupal, assume um caráter insondável e indizível. Parece mesmo que a violência, como um causar mal, como um fazer sofrer, nos é original, ou seja, não é algo que nos acrescenta, mas algo que simplesmente está em nós, nos

\footnotetext{
3 Destacamos aqui em particular as reflexões expressas nos livros organizados por Ricardo Antunes: Riqueza e miséria do trabalho no Brasil, Riqueza e miséria no trabalho no Brasil e Riqueza e miséria do trabalho no Brasil III.

4 Segundo Agamben (2010, p. 40-41), "dispositivo é qualquer coisa que tenha de algum modo a capacidade de capturar, orientar, determinar, interceptar, modelar, controlar, e assegurar os gestos, as condutas, as opiniões e os discursos dos seres viventes. Não somente, portanto, as prisões, os manicômios, o panóptico, as escolas, as confissões, as fábricas, as disciplinas, as medidas jurídicas etc, cuja conexão com o poder é em um certo sentido evidente, mas também a caneta, a escritura, a literatura, a filosofia, a agricultura, o cigarro, a navegação, os computadores, os telefones celulares e - porque não - a linguagem mesma, que é talvez o mais antigo dos dispositivos, em que há milhares e milhares de anos um primata - provavelmente sem dar-se conta das consequências que se seguiriam - teve a inconsciência de se deixar capturar."
} 
compõe e confere pelo simples fato de existirmos: está como uma potência e devir. A violência é possuidora de um fundo enigmático que nem a razão - ciência nem a Ponerologia (LOBACZEWSKI, 2006) - poneros do grego = mal - é capaz de penetrar, pois ela se nega à submissão, ao jogo de leis físicas ou psíquicas ou a reduções estatísticas ao modelo do pensamento simplificador, embora se presta e se serve destas. A Ponerologia cumpre os requisitos do princípio do remédio: "Ignoti nulla curatio morbi", ou seja, não tente curar o que você não entende. A maneira mecanicista de conceber a violência, que a descreve como realidade fechada e completa, evidencia os limites e as insuficiências da ciência clássica como modelo explicativo e, provavelmente, é um dos motivos por não conseguirmos curar o que pensávamos entender em plenitude.

Para Queiruga (2001, p. 182), “[...] por sua própria natureza, o mal aparece como facticidade irredutível e contraditória: como aquilo que não devemos ser e que, no entanto, é." Estamos e somos seres humanos constituídos e constitutivos de realidades, e participamos de uma humanidade que se realiza também em violência, como violência.

ser humano contemporâneo, no seio da civilização, vive cercado de ambiguidades, contradições, paradoxos e desigualdades que expressam e renovam formas de violência, intempestivamente. Reencontramo-nos, no agora, com os mesmos horrores, as mesmas angústias e as mesmas desesperanças de antes e as elasticamos para o amanhã. Pode-se afirmar que o mundo, a sociedade e os humanos estão feridos pela violência, a violência da injusta distribuição dos bens, a violência do abuso do poder e da crueldade cometida em nome de uma única verdade. A possibilidade do inumano faz parte do humano.

Um inumano que se manifesta, como defende Bauman (1998), na violência do desejo de consumir, na violência pela busca do poder, pela orquestra absoluta do poder da tecnociência, como uma espécie de resposta à ânsia de realização e de felicidade. Diante de todos eles nos vemos envolvidos em outra violência, o reconhecimento do quanto são parciais, do quanto não preenchem a nossa vida - a violência das coisas finitas -, sejam eles de relações nas redes eletrônicas, em relações sexuais, via consumo de alimentos, via consumo de bens mercantis, como celulares, smartphones, ipads, tênis, entre outros. 
Da mesma forma, aperfeiçoamos racionalmente as técnicas da violação moral violentando consciências pela dessubjetivação. ${ }^{5}$ Elasticando a violência da carência, sequestrando a esperança e a confiança, criando dispositivos de vigilância, controle e punição. Reduzimos o ser humano à sua condição de Homo sacer - vida nua, zoé - tirando-lhe a máscara cultural para transformá-lo numa marca estatística, um número expresso em plástico, a biometria, a biopolítica, ${ }^{6}$ o biopoder, ${ }^{7}$ uma identidade sem pessoa (AGAMBEN, 2010), que sintoniza com os anormais, o bando e a exceção. ${ }^{8}$ A frustração e o desespero fazem capitular milhões de pessoas que, arcadas pela violência,

5 prefixo des indica separação e negação, um processo de negação do elemento subjetivo. A dessubjetivação evidencia um sujeito fraco, porque transformado em sujeito-objeto, a favorecer interesses mercantilistas, ou ainda reduzido a um ser de desejos, habitado por forças impessoais, mas, também, um ser individualista e solitário, um ser privado, como sinaliza Touraine (2002). Pela dessubjetivação as potencialidades subjetivas do trabalhador se apresentam como independentes e hostis a ele, como pertencentes a um outro. Ela reforça o caráter hostil e estranho que, na produção capitalista, reduzem a subjetividade ao estatuto de coisa.

6 Segundo Ruiz (2012), a expressão Biopolítica (cálculo que o poder faz sobre a vida) foi criada pelo pensador sueco Rudolph Kjellen. Segundo Ruiz (2012, p. 41), a genealogia conceitual de biopolítica remete diretamente a uma de suas consequências mais perversas: a destruição das vidas inúteis em nome do crescimento das vidas melhores. Assim, para Kjellen, a biopolítica deriva imediatamente numa tanatopolítica (cálculo do poder sobre a morte). A tanatopolítica se justifica como uma política de mortes seletivas com objetivo de "cuidar" a vida dos cidadãos melhores ou mais importantes. Ela não se legitima como um poder despótico arbitrário, mas como uma política eugenista para o bem da maioria dos cidadãos. $\bigcirc$ objetivo biopolítico da tanatopolítica é defender a sociedade de "vidas indignas de ser vividas" e de "vidas perigosas". Foucault resgata o conceito e, através dele, realiza uma "arqueologia dos saberes e práticas modernas que fizeram da vida humana um objeto útil de governo." Para Foucault (1988), a biopolítica designa aquilo que faz com que a vida e seus mecanismos possam entrar no domínio de cálculos explícitos, e o que transforma o saber-poder num agente de transformação da vida humana.

Biopoder: criada por Michel Foucault, a expressão indica a centralidade, na consolidação do poder na modernidade, daquilo que Foucault chama de "administração dos corpos" e de uma gestão calculada da vida (FOUCAULT, 1988). Para Foucault, a transformação da vida humana em objeto do poder soberano implicou a redução desta à condição de pura biologia, uma vida pronta para ser administrada pelos dispositivos ordenadores do poder. Para Agamben (2002), significa a redução à "vida nua", pura zoé, ou seja, a vida nua é a vida matável e insacrificável do Homo Sacer. autor afirma a existência de dois mundos, o mundo dos direitos e aquele das "exceções", o mundo dos corpos que devem ser cuidados e o mundo habitado por aqueles que têm o estatuto de vida nua, de vidas postas fora da jurisdição humana de modo tal que a violência cometida contra eles não constitui nenhum sacrilégio. Para Arendt (1985), se a condição humana é definida pela vida política e pelo diálogo argumentativo entre iguais, o zoon logon ekhon - o ser vivo capaz de fala -, seu contrário, o que caracteriza a vida nua e sem ação política é o aneu logou - sem logos, sem fala -, uma vida sem significação alguma, uma vida que se esgota no próprio fato da sobrevivência, na sua característica única de ser vivo, pura biologia.

8 A figura dos anormais, incorporada à categoria de degeneração, inscreve-se nas margens do jurídico. Por seu caráter de "exceção". A relação de exceção é uma relação de bando. Aquele que foi banido não é, na verdade, simplesmente posto fora da lei e indiferente a esta, mas é abandonado por ela, ou seja, exposto e colocado em risco no limiar em que vida e direito, interno e externo, confundem-se (AGAMBEN, 2002). 
tornam-se presas fáceis de forças e poderes hegemônicos e perversos que as sugam sem escrúpulos, para cooptá-las a interesses traiçoeiros e ajustá-las, tal qual uma peça, ao grande sistema objetificador (AGOSTINI, 2001). Um poder soberano que realiza manobras violentas em todas as instâncias, nas mais diversas esferas e locais, que converte a desigualdade em processo natural e algo inevitável, num mundo que se concebe globalizado.

Benjamin (2005), em sua Tese VIII, Sobre o conceito de história, escreveu que, para os oprimidos o estado de exceção é a norma. Uma sentença que capta com perfeição um dos desdobramentos das consequências da exceção como forma de controle biopolítico, a violência legalizada. Os oprimidos vivem essa condição como parte de seu modo de vida. Uma realidade que pode ser constatada nas sociedades nas quais a exclusão e os privilégios se perpetuam geração após geração, como se fossem uma espécie de fatalidade natural sobre os oprimidos e violentados, como algo profundo e intenso, que irá se estender a seus descendentes.

Todas essas formas de violência nos deixam dilacerados e nos jogam no vazio da incompreensão diante do espectro das mortes prematuras, no vazio da solidão, na indizível e já globalizada indiferença (A GLOBALIZAÇÃO.... 2013). A crise cultural, resultante de interesses ocultos em manter boa parte dos seres humanos na esfera da alienação via fragilização de sua capacidade de pensar, bem como a crise existencial como falta de sentido para a vida e a desesperança, sinalizam o registro dos desencantos do ser humano. Diante da sensação de vazio interior, a grande falta de esperança ocasiona a fadiga do viver, com implicações diretas no aumento da ansiedade, do estresse e outras enfermidades psicoafetivas. A violência do utilitarismo instrumental, do eficientismo e da cronometria atrozes faz desaparecer o horizonte das crenças e dos grandes relatos, radicalizando a violência no mundo e acelerando o desequilíbrio nas cotas normais da agressividade humana. Os cenários de frustração remetem e polarizam mais violência, nas mais diferentes faces, como terrorismo, enfrentamentos étnicos, agressividades religiosas, aumento de delinquência e violências urbanas, corrupções de todos os matizes.

Nem as parcerias, como que um absoluto com as tecnologias e nelas o endeusamento humano, não foi eficaz na minimização das violências, das 
indiferenças e da solidão, como também não são suficientes para impedir que milhões de seres humanos sejam violentados pela miséria e morram de fome. Não estamos sendo capazes de oportunizar a cada ser humano uma existência digna e nem de pôr fim às crescentes ondas de violência. $\bigcirc$ poder da tecnociência não anda de mãos dadas com o potencial humanitário na medida em que se constitui em estratégia de controle e fechamento do poder do ser humano assumido enquanto domínio. Para Heidegger (1995), a tecnociência levou ao esquecimento do ser, da condição humana de abertura. No império da tecnociência, o sujeito reduzido a objeto é dissolvido em prol da disponibilidade, da manipulação e da apropriação. Para Heidegger (1995), a articulação entre o ser humano e a tecnociência não é uma relação de ferramenta, mas de consumação, ou seja, consome-se o ser consumindose no ser. Ainda, a tecnociência violenta a condição humana, por recusa à permanência na imperfeição, no inacabado, uma vez que nas tecnologias digitais radica a capacidade de os objetos tecnológicos repararem a sua própria deficiência.

Ainda, e apesar de sua disseminação arbitrária, indiscriminada e desproporcional, a pergunta sobre o porquê das violências não se faz calar, ou seja, por que os processos culturais e o regramento social são ineficazes no controle dos impulsos destrutivos? As reflexões sobre violência, como simplesmente uma problemática humana e universal, são necessárias, uma vez que permitem diferentes aproximações, sempre insuficientes, um complexo de saberes dispersos, mas ainda assim importantes e necessárias.

Diante desses cenários, radicados em violências de múltiplos matizes, o trabalho reflete sobre as emergências de diferentes racionalidades e emocionalidades, frutos ou não do desenvolvimento científico, como convites epistemológicos, mesmo que indeterminados, mas profunda e rizomaticamente ${ }^{9}$ enredados, para compreender melhor a complexidade do

9 Segundo Deleuze e Guattari (2000, p. 36), "um rizoma não começa nem conclui, ele se encontra sempre no meio, entre as coisas, inter-ser, intermezzo. A árvore é filiação, mas o rizoma é aliança, unicamente aliança. A árvore impõe o verbo 'ser', mas o rizoma tem como tecido a conjunção 'e... e... e...' [...] move-se entre as coisas, instaura uma lógica do E, reverte a ontologia, destitui o fundamento, anula fim e começo [...] o meio não é uma média; ao contrário, é o lugar onde as coisas adquirem velocidade. Entre as coisas não designa uma correlação localizável que vai de uma para outra e reciprocamente, mas uma direção perpendicular, um movimento transversal que as 
mundo, a complexidade dos fenômenos sociais e históricos, a complexidade da condição humana, também envolta em violências que, mesmo irreversíveis, postulam probabilidades. Assim, em meio às inflexões da complexidade da condição humana perguntamos: como violência e epistemologia estão articuladas e como uma dimensão epistemológica pode constituir-se para além de ser expressão violenta e da violência?

Pretende-se caminhar num viés epistemologicamente aberto, como forma de negar e pensar uma epistemologia para além das lógicas simplistas e excludentes. Olhar para diversas faces da violência como possibilidade de redesenhar, mesmo sendo essa uma tarefa inglória, diante da incompletude desse desenho, mas, ainda assim, de relevante importância. Aventurar-se nessa empreitada é acenar com diferentes possibilidades de refletir, discutir e lidar com uma das inglórias faces da dimensão humana: a capacidade de exercitar e exercitar-se em violência no âmbito do conhecer. Ao conjugar a epistemologia em conceitos como os de complexidade e com outros conceitos emergentes, deseja-se extrair deles um potencial suporte para amplificar reflexões com aberturas para diferentes sensibilidades visando compreender melhor a diversidade da vida humana envolta nos braços da violência.

\section{HÁLITO DA UIOLÊNCIA: UMA CONFUNDÍUEL CONDIÇÃO HUMANA}

Morin (2003), referindo-se à natureza e biologia humana, destaca que as grandes emoções como o amor, a raiva, a ternura, a agressividade e outras são efetivamente universais e intrínsecas a todos os humanos. Para o autor, carregamos ao mesmo tempo o melhor e o pior da espécie, cabendo ao processo cultural inibir e exibir as emoções para que a vida em sociedade seja possível. As culturas, que no processo formativo enaltecem emoções como a agressividade, certamente prosperam num grau maior de violência. Sobre a violência, Rocha (1996, p. 10) escreve:

carrega uma e outra, riacho sem início nem fim, que rói suas duas margens e adquire velocidade no meio." 
A violência, sob todas as formas de suas inúmeras manifestações, pode ser considerada [...] como uma força que transgride os limites dos seres humanos, tanto na sua realidade física e psíquica, quanto no campo de suas realizações sociais, éticas, estéticas, políticas e religiosas. Em outras palavras, a violência, sob todas as suas formas, desrespeita os direitos fundamentais do ser humano, sem os quais o homem deixa de ser considerado como sujeito de direitos e de deveres, e passa a ser olhado como um puro e simples objeto.

Segundo Queiruga (2001), inexiste a possibilidade de um mundo sem maldade, sem violência. Para a modernidade vale a imanentização da violência, ou seja, as causas de quaisquer ações violentas são buscadas em realidades humanas. No predomínio da lógica racional ninguém busca as causas de um assassinato, ou as causas das torturas, do holocausto, ou do terror em fontes extramundanas, como as magias e os mitos, ou em crenças religiosas. Buscamos explicações para os atos de violência e as podemos atribuir, por exemplo, a decisões políticas.

Considerando a tese defendida em vários momentos de que "[... num mundo tal como é e o conhecemos o mal é algo inevitável [...]" (QUEIRUGA, 2001, p. 315), o autor ainda questiona sobre a possibilidade da existência de um mundo sem violência e maldade "seria possível um mundo diferente no qual não houvesse conflitos, rupturas, crimes e sofrimentos", isto é, um mundo sem violência? (QUEIRUGA, 2001, p. 315). Benjamim (201 l, p. 138) igualmente se questionava: "[...] será que a resolução não-violenta de conflitos é um princípio possível? [...]", e ele se posiciona como favorável se admitirmos a cortesia do coração, o amor à paz, a convivência na confiança e no diálogo, no alicerce da linguagem e da compreensão mútua.

A violência é algo que explode, é imprevisível e repentina, um fenômeno do "absurdo", tido como atitude de loucura, um desvario, pressente em meio às múltiplas dimensões do humano. Imaginado muitas vezes como encarnação do mal e do pecado, ela tem uma função estruturante e essencial de qualquer aspecto da realidade humana. Ela é uma dimensão da humanidade (DADOUN, 1998), que revela e evoca o humano para além e para aquém de si. 
A palavra violência é de difícil definição, mas a sua pluralidade de acepções pode trazer alguns elementos que ajudam em esclarecimentos e construções compreensivas. Considerá-la prenhe de uma pluralidade de concepções significa reconhecer a impossibilidade de sua homogeneização e redução, que tendem a buscar a ordem e a definir a ordem como algo pretensamente clarificadora e hierarquizada. Essa tendência desconsidera a ambiguidade e convida a ignorar a complexidade, uma vez que a violência apresenta traços de desordem, de indeterminações, incertezas, desequilíbrios, dinamismos, entre outros que convocam, invocam e impulsionam o humano para além do dado como humano, como inumano. Isso não significa colocar a violência como algo positivo, mas como uma possibilidade dimensional do humano, no âmbito do poder ser, não como domínio.

Etimologicamente, a palavra violência procede do substantivo latino violentiae, significando veemência e impetuosidade. Ela remete a vis, que significa força, do mesmo modo que o termo grego correspondente - $\beta i ́ \alpha-$ também pode significar força vital e, conforme Dadoun (1998), vis demarca o 'caráter essencial', ou seja, a 'essência' de um ser. Etimologicamente, violência mostra algo que pode ser estendido para o mundo vital não humano, como para fenômenos físicos, por exemplo, a força das águas ou a força do vento numa tempestade (PEREIRA et al., 2000).

A etimologia também indica uma perspectiva antropomórfica, uma vez que o substantivo latino violentiae está ligado ao verbo violare, que origina "violar", significando infringir, transgredir, desonrar, desrespeitar, profanar, tratar com irreverência coisas sagradas, devassar, como em "violar um segredo". O verbo grego violar também significa "transgressão" (PEREIRA et al., 2000), e considerando a fonte etimológica da palavra "violência" e o seu vínculo com a transgressão e a profanação, percebe-se uma relação essencial com o normativo e o sagrado, como tudo, como expressão do poder ser, possibilidade do poder ser (diferente de poder enquanto domínio), mesmo que em demasia desse poder ser.

No pensamento grego, a falta de medida, a desmesura e o excesso nos seres humanos os fazem transgredir a medida verdadeira, como a justiça e a lei divina, expressões da ordem sagrada do mundo e também sustentos da justiça e das leis humanas. 
Em A violência, Dadoun (1998) reflete sobre o homo violens e se questiona sobre as raízes da violência, sobre o nascedouro do medo, do pânico e do controle. $\bigcirc$ autor considera a violência como essência do humano e dirige-se ao ser humano como Homo violens, em contraposição ao Homo sapiens, um ser de razão. $\bigcirc$ Homo violens é "[...] o ser humano definido, estruturado, intrínseca e fundamentalmente pela violência." (DADOUN, 1998, p. 8). Segundo Dadoun (1998), o Homo violens é o foco central de coesão em torno do qual orbitam o Homo sapiens, o Homo faber, o Homo laborans, o Homo ludens, o Homo politicus e demais variações do gênero Homo, uma trajetória humana cuja epopeia se fez e se faz sob a égide da violência.

Para Drawin (2011), a etimologia tende a indicar ser a violência, como transgressão e profanação, não um fenômeno da natureza (physis), mas um fenômeno próprio da cultura (ethos). Significa dizer que os animais são agressivos, porém somente o humano, que partilha a agressividade com os animais, pode ser considerado violento. Partindo desse pressuposto, Drawin (2011) apresenta três enunciados em defesa de sua tese de que a violência é um paradoxo. Primeiramente, sendo a violência uma condição antropológica, um fenômeno humano, e considerando que a condição humana se concebe tendo como base essencial a cultura, então a violência vincula-se à cultura, como poder enquanto forma de domínio.

Emseu segundo enunciado, e considerando ser a cultura uma construção material e simbólica complexa, emergente do e no processo evolutivo, ela tende a compensar e a superar fragilidades biológicas e desamparos psicológicos da espécie Homo. Assim, se a cultura está a serviço da vida humana e se a violência é intrinsecamente vinculada à cultura, então ela produz as condições de vida e de violência, ou seja, estranhamente a cultura parece negar-se a si mesma. Desse negar-se a si mesma, Drawin (2011) elabora seu terceiro enunciado. Afirma que é nessa contradição que acontece não somente a transformação, mas a autoafirmação da cultura. E se a violência é um imanente cultural, então o seu desenvolvimento histórico não é algo linear que, gradativamente, deixaria a violência para trás, como se fosse um estágio primitivo ou uma espécie de resíduo da animalidade humana. Sendo a violência uma coextensão da cultura, ela não ocorre na natureza, mas no mundo humano. A violência, como própria do ser 
humano e cultural, contém dimensões éticas, e isso a distingue da agressividade instintiva. Por isso, ela carrega uma variabilidade de significados de acordo com os contextos sócio-históricos.

Mas questiona Drawin (201 1), se cultura e violência são parceiras em construção e o desenvolvimento cultural "não exorciza o fantasma da violência", não cairíamos num determinismo fatalista e num conformismo, ou mesmo em atitudes de indiferença diante da inevitável violência?

Nessa visão multifacetada a violência é um produto resultante e detonante das inúmeras e complexas relações auto-eco-organizativas ${ }^{10}$ (MORIN, 2010) do processo evolutivo humano, sempre aberto para novas emergências e novas convergências, enredado num todo e dinâmico sistema. Prestar atenção aos aspectos da incompletude conceitual sobre violência é um dos modos de vislumbrar o movimento misterioso e imprevisível que cria a violência interhumana e intra-humana e mantém uma coesão da humanidade no inumano. Já não cabem contentamentos com meras descrições dos fenômenos da violência, é preciso trabalhar sua problemática, ou seja, compreender epistemologicamente suas articulações estruturais, seus destinos e suas ligações com as realidades sócio-históricas. Ou seja, aprofundar reflexões sobre: sendo a epistemologia uma expressividade do humano, como ela se constitui em expressão violenta?

\section{EPISTEMOLOGIAA E UIOLÊNCIA}

Vamos considerar, como hipótese, a afirmação de Maturana (2001, p. 57): "As explicações científicas não se referem à verdade, mas configuram um

\footnotetext{
10 Morin apoia-se em Von Neumann e Von Förster para ampliar o conceito de auto-organização. De Von Neumann utiliza as ideias de autorreparação, autotransformação e de autorreprodução, vistas como propriedades características dos seres vivos que não são somente capazes de tolerar uma desordem, mas de se alimentar dessa desordem para se regenerar. Morin entendeu que os meios usados como regeneradores são extraídos do entorno ambiente. Von Förster mostrou, nos anos 1960, a existência de um paradoxo na ideia de auto-organização, uma vez que reconheceu a necessária existência de fontes de energia externas, e Morin ampliou o conceito de auto-organização para a auto-eco-organização.
} 
domínio de verdade [...] A ciência é um domínio cognitivo válido para todos aqueles que aceitam o critério de validação das explicações científicas."

Já na Grécia antiga, Platão (427-347 a.C.) escreve que o conhecimento é a crença verdadeira que pode ser fundamentada por meio de um relato ou uma explicação. Também foi importante, na Grécia antiga, a discussão epistemológica feita pela presença dos céticos, que incorporaram proposições de sofistas como Protágoras e Górgias quanto à radicalidade em negar a possibilidade de estabelecer o que era verdadeiro e falso, certo ou errado.

A epistemologia passa por uma profunda reformulação a partir do século XVII. A sociedade renascentista europeia foi afetada por diversos e inéditos acontecimentos, como, por exemplo: no plano político com a formação de Estados unificados; no plano econômico, com o desenvolvimento das Grandes Navegações e a Revolução Industrial; e no plano religioso, com a Reforma Protestante. Articula-se na dimensão cultural, com a redescoberta da antiga cultura grega e latina, bem como com o desenvolvimento do pensamento científico, a Revolução Científica com Bacon (1561 - 1626) e com Galileu (15641642), o pensamento filosófico moderno, com René Descartes (1596-1650), e a Filosofia Iluminista. Essa ampla mudança epistemológica fez com que a modernidade inaugurasse uma diferente forma de relações entre os seres humanos, sendo o poder e a violência as formas de dominação que cresceram de forma vertiginosa, quanto mais difícil se torna lidar com contingentes populacionais diversos e numerosos.

Epistemologia significa "estudo da ciência", vem do grego episteme (ciência, conhecimento científico) e logos (palavra, verbo, estudo, discurso, teoria). Estuda a origem e o valor do conhecimento humano em geral. Também pretende significar o estudo das ciências (físicas e humanas), os princípios que as fundamentam, os critérios de verificação e de verdade, bem como o valor dos sistemas científicos. Diz respeito aos processos do conhecimento, ao conhecer.

Pode-se afirmar que epistemologia é a filosofia da ciência. Não propriamente o estudo dos métodos científicos - objeto da Metodologia Científica. Epistemologia é essencialmente o estudo crítico dos princípios, das hipóteses e dos resultados das diversas ciências, destinado a determinar 
a sua origem lógica, o seu valor e a sua objetividade (ZILLES, 2008). Também é oportuno distinguir, como sugerem pensadores, a Epistemologia da Teoria do Conhecimento. Esta tem por objetivo buscar a origem, a natureza, o valor e os limites do conhecimento, da faculdade de conhecer. Assim, a Teoria do Conhecimento é mais ampla, abrangendo todo tipo de conhecimento, enquanto a epistemologia se limita ao estudo sistemático do conhecimento científico, sendo, por isso mesmo, chamada de filosofia da ciência (SANTOS, 1960).

Também vamos referenciar rapidamente a Epistemologia Evolucionária, cuja expressão admite dois significados diferentes, não contraditórios, mas complementares. Num sentido mais geral, a evolução humana e neural; suas formas são assunto-chave para a epistemologia, já que, ao moldar nossos sentidos e toda a nossa corporeidade, deu origem às bases biológicas dos processos cognitivos. Segundo, um sentido mais específico: as próprias formas do conhecimento, as linguagens, as culturas, as ideias, teorias e modos de percepção formam parte de processos evolutivos cujos padrões podem ser estudados tanto a partir das ciências naturais quanto das humanas e sociais. A epistemologia evolucionária toma para si o desafio de compreender melhor os “contextos evolucionários da história da nossa espécie e os nichos vitais em que os seres humanos concretos de hoje surgem para a vida." (ASSMANN, 201 l, p. 52). Particularmente aqui cabe destacar tratar de uma tentativa de aproximação entre a pedagogia e as biociências e superar a visão dualista corpo e mente como enunciado no escrito de Assmann (201 1, p. 53): "Nossa evolução orgânica foi toda ela uma evolução cognitiva, na qual desde sempre coincidiram processos vitais e processos cognitivos. Assim, oriundos de aprendizagens, ser aprendentes é a nossa natureza e história, e nossa maior dignidade."

A epistemologia como modo de pensar, como forma de compreender nossa história de transformações culturais é constituinte e constitutiva de visões de mundo, definidora de nossas dinâmicas emocionais e racionais. A epistemologia configura nossa existência individual e social, é uma tentativa de elucidar nossas coerências do viver cotidiano e nossas experiências humanas, questiona nossas cegueiras, nossa condição de observadores no observar, criar e compreender fenômenos biológicos, as coisas, a materialidade e a nossa 
imersão cambiante em multiversos linguajantes, no sentido de conferir bases mais seguras às ações humanas.

Tendo como referência o multiverso das linguagens, das experiências de mundo, podemos conceber a epistemologia como uma tentativa de formalizar linguagens - enfoques, conceitos e sistematizações teóricas - sobre as formas argumentativas que criam realidades e não somente como formas diferentes de se ler a realidade. É uma espécie de via conceitual que permite conhecer a cognoscibilidade e significar os sentidos das coisas e da vida, considerando que podem se apresentar como formas janelares de conhecimentos a serem admitidos como "verdadeiros" e/ou científicos num determinado espaço e tempo.

Se as realidades são argumentos explicativos resultantes das nossas experiências linguajantes, ${ }^{11}$ então, as ideias acerca das realidades não são as próprias realidades. Todos os conceitos, concepções e teorias, por nós construídos, são efetivamente "ferramentas epistemológicas do ser humano e para o ser humano." (ASSMANN, 2011, p. 88). As realidades, os mundos conhecidos coincidem com os arcabouços das ações em que embutimos e movemos nossas linguagens. Epistemologicamente falando, todas as realidades nada mais são que realidades inventadas por nós. ${ }^{12}$ Dessa forma, os limites de nossas linguagens delimitam as nossas realidades. Ainda epistemologicamente falando, todo e qualquer conhecimento resulta e não passa de uma determinada modelização criando definições, teorias e realidades.

É importante reconhecer a transitoriedade, a incompletude, a contextualização e o caráter histórico para evitar perder-se na ilusão de que temos acesso absoluto à verdade e à realidade das coisas. As realidades, em cada espaço e marco temporal, coincidem com o tipo de pergunta, admitida como relevante, que a humanidade se coloca, em determinado espaço e marco temporal. Pode-se dizer que vivemos em coevolução porque

\footnotetext{
11 Linguagem aqui entendida nos termos propostos por Maturana (1998, p. 200), para quem "o fenômeno da linguagem tem lugar quando um observador distingue, nas interações de dois ou mais organismos, coordenações condutuais consensuais de coordenações condutuais consensuais. Quer dizer, a linguagem surge quando há recursão no âmbito das coordenações condutuais. A partir disso, se deduz que a linguagem sugere e se estabelece como fenômeno social, e que as palavras são coordenações de ação, não entidades abstratas ou referências a entidades independentes."

12 Referência ao livro organizado por Paul Watslawick (1994).
} 
nos permitimos criar concepções transversais que potencializam diferentes sentires e diferentes fazeres.

Assim concebidos referem-se a rupturas, cisões e transformações na forma de compreender-nos. Toda ruptura decorre da existência de um conjunto de problemas, cujas soluções já não encontram cobertura num determinado campo teórico e diferentes debates, diferentes ideias, diferentes articulações; buscas e reconstruções passam a acontecer a partir de também diferentes fundamentos que se efetivam no âmbito da experiência, como experiência.

Trata-se de uma estranheza, de uma desconexão ou mesmo de uma dissociação, com presença marcante na pós-modernidade e na contemporaneidade, uma predisposição para "[...] perceber não as luzes, mas o escuro [...]" (AGAMBEN, 2010, p. 62), porque entendemos que a lógica do pensamento moderno chegou ao seu termo. Agamben (2010, p. 63) afirma que esse olhar o escuro, essa ausência das luzes da razão não significa uma impossibilidade de visão, nem potencializa "uma forma de inércia ou de passividade, mas implica uma atividade e uma habilidade particular que, no nosso caso, equivalem a neutralizar as luzes que provêm da época para descobrir as suas trevas, o seu escuro especial, que não é, no entanto, separável daquelas luzes." Torna-se evidente a insuficiência da racionalidade moderna construtora de verdades e de certezas enquanto é também um convite para uma necessária rendição à relativização.

A partir de 1900, gradativamente, iniciamos um processo de tentativas visando evitar sermos cegados pelas luzes do racionalismo, para conseguir "[...] entrever nessas a parte da sombra, a sua íntima obscuridade [...]" (AGAMBEN, 2010, p. 63-64). Muitas foram as experiências dessa necessária relativização, o desconexo marcou vidas e organizações humanas, sendo em inúmeros casos o anonimato um legado desse "não mais" e ao mesmo tempo desse "ainda não". Ainda assim, podemos referenciar o físico Max Planck que introduziu o conceito de átomos de energia ou quantum, originando a mecânica quântica e levantando uma série de questões, não especificamente relacionadas aos problemas físicos, mas também às ciências naturais e à natureza da matéria. Essas questões levaram físicos e outros cientistas a reconsiderar os problemas 
filosóficos, em especial aqueles pertinentes à essência da matéria e aos problemas de natureza epistemológica.

É no contexto de descobertas relacionadas à Teoria da Relatividade e à Teoria Quântica que ocorre o esfacelamento dos principais conceitos da visão de mundo cartesiana e da mecânica newtoniana, tanto no que se refere à noção de espaço e tempo absolutos, às partículas sólidas elementares, à objetividade científica, à causalidade e à separatividade. Destaca-se a necessidade de uma visão de mundo como um todo indiviso, no qual todas as partes do multiverso se fundem, incluindo o observador e seus instrumentos. Observador, objeto observado e processo de observação constituem uma totalidade indivisa em movimento fluente e dinâmico, caracterizando o efetivo estado das coisas.

Reflexões e discussões abertas consideram a incompletude, a indeterminação, a complementariedade, ou seja, a complexidade e a emergência. $\bigcirc$ Teorema da Incompletude de Gödel é um indicativo do quanto é frágil e insuficiente a opção da ciência moderna, por afirmar a impossibilidade de, na clausura disciplinar, fundar, de forma completa, uma definição para qualquer sistema conceitual. Assim, no contexto da complexidade é pertinente desconfiar da concepção ingênua sobre a realidade, seja ela física, social, ambiental ou humana.

Diante das diferentes evidências de que tanto o tempo quanto o espaço tendem a não somente se relativizar, mas serem interdependentes, reconhecer a perda de sua singularidade existencial, como distintos e independentes, para um transfundo de interdependências, importa mudar e recompreender a noção de realidade. Mudança que seja capaz de admitir ser a realidade física, a realidade biológica, a realidade social e humana uma totalidade de interconexões, um complexo rizomático, um algo indisível e indedutível, porque incapaz de separação, incapaz de distinção, incapaz de determinação, um todo multifacetado e, por isso, indeduzível.

Na contemporaneidade fluida e nebulosa, soa relevante permitir-se o reconhecimento dos limites de nosso entendimento e de nossa compreensão, ou seja, reconhecer os limites, as fragilidades e as insuficiências da razão humana. A desconfiança das apostas que afirmavam sermos com base racional, 
capazes de dar conta da realidade, abre-se para concepções de que o modo de ser e estar no mundo implica, para além da fria lógica racional, relações intersubjetivas sensibilidades e emocionalidades.

$\mathrm{Na}$ presença dessa totalidade indivisa, e num mundo ferido pela violência, num mundo manchado pela violência da desigual distribuição dos bens, num mundo maculado pela violência do poder - biopoder -, num mundo doente pela incapacidade de relacionar-nos, por que assentado num vazio interior, num mundo enfermo pela degradação política e regalos da corrupção, faz sentido retomar e ampliar também as reflexões e discussões sobre a temática da violência e considerar sua incomensurabilidade. A violência do estilo e jogo consumista, embora silenciosa, é perceptível por meio do reaparelhamento da polícia, aumento do efetivo militar e gastos com defesa pública e privada. Bauman (1998, p. 25) destaca que "os consumidores falhos ou refugos do consumo são cercados por câmeras, muralhas e vigilância constante a fim de não perturbarem os consumidores afortunados e felizes." A despeito, Elias (1993) defende que o prazer da crueldade, da destruição e do tormento de outrem, socialmente permitido por milênios, hoje se apresenta mais refinado e menos festivo.

A linguagem como criadora de realidades criou as violências reconhecidas como subjetivas, aquelas que se referem a crimes, terror, confrontos e guerras. Porém, existem as violências objetivas, aquelas que estão presentes nas relações de dominação social, construtoras de desigualdades e conservadoras de privilégios, são linguagens que impõem um determinado discurso de sentidos, visões de organizações hierárquicas, reguladoras das lógicas dos sistemas políticos e econômicos. Segundo Zizek (2014, p. 26), são as violências objetivas que implicam a "[...] criação 'automática' de indivíduos excluídos e dispensáveis (dos sem-teto aos desempregados) [...] dos novos 'fundamentalismos' emergentes, de caráter étnico e/ou religioso e, em última instância, racistas." Trata-se de uma violência anônima e, por isso, objetiva que ninguém planeja, ninguém executa. É nesse viés de violência objetiva que entendemos existir também a violência epistemológica, uma vez que a epistemologia objetiva também parte do princípio de que a realidade existe em si, independentemente do observador, transformado em objeto. Transformado 
em objeto, pois diante da pretensão de universalidade eliminam-se as singularidades do ser humano sujeito e aprendente. Veremos isso melhor na sequência.

Se os contextos das realidades construídas acontecem no multiverso de relações intersubjetivas, emergem das e nas experiências de vida, em vida, como coerências operacionais do manter-se vivo. Então, já não existe uma realidade "lá fora" e nem como olhar para a realidade como algo único, cuja existência é objetiva, determinada a priori e independente de um observador. Significa dizer que diferentes teorias ${ }^{13}$ (teoro, do grego theorós = espectador, viajante para ver o mundo), como se fossem diferentes fachos de luzes, já não iluminam e nem permitem acessos privilegiados à realidade. Teorias já não são jeitos diferentes de ler uma dada realidade, pois esta não existe em si e objetivamente, ou seja, independente de um observador. Segundo Maturana (2001, p. 37), "A realidade é uma proposição explicativa." Se a realidade é uma proposição explicativa, então existem muitas realidades. Admitir a existência de muitas realidades implica admitir que as afirmações cognitivas são validadas pelas coerências operacionais que constituem o observador. São essas coerências operacionais que legitimam a explicação, num contexto que Maturana (2001) denomina "caminho da objetividade entre parênteses." Nesse caminho, toda explicação é uma reformulação das experiências do observador com elementos da sua experiência. Por sua vez, "No caminho da objetividade sem parênteses" as afirmações são feitas independentemente da experiência do observador. Por isso, afirma Maturana (2001, p. 36), "Neste caminho explicativo, toda afirmação cognitiva é uma petição de obediência." É no caminho da objetividade sem parênteses que a violência epistemológica ganha forma. Afirmações objetivas têm como princípio de que tenho acesso à realidade, cuja existência independe de mim. Esse acesso, como um acesso privilegiado à realidade, reforça a concepção de que "o que dá validade à minha afirmação é aquilo que eu posso dizer que tem a ver com algo que é independente de

\footnotetext{
13 Segundo Machado (2003), em seu Dicionário Etimológico da Língua Portuguesa, teoria deriva do verbo theoréo (examinar, observar, inspecionar) e tem relação direta com a palavra Théia (visão) e com o verbo o theaomaí (contemplar, mirar visionar). A palavra grega theoreîn significa olhar através de, aquele que olha é chamado de theorós (espectador). Assim, tem-se: Theoreîn = théa (através) + horós (ver).
} 
mim." (MATURANA, 2001, p. 35). É nessa base racional, que me permite o acesso à realidade exterior, que radica a violência epistemológica, e "nessas circunstâncias, aquele que não está comigo está contra mim. Está equivocado [...] porque é cego, porque é cabeça dura." 14 autor segue afirmando que "Eu não sou responsável pelas coisas serem assim: são assim, com independência de mim, e isso é o que dá poder ao meu conhecimento." (MATURANA, 2001, p. 35). Uma violência epistêmica, que ocorre no âmbito do sujeito e também no âmbito do objeto como unilateralização dos polos, seja do fechamento objetivo e sintético dos processos, das subjetividades e objetividades autoencerradas e em si absolutizadas que não permitem a conversação.

Falar objetivamente significa exigir que todos façam o que e como "eu" digo, "uma vez que a validade do exigido não depende de mim, mas é própria do indicado, e "eu" tenho acesso privilegiado a essa realidade." (MATURANA, 2001 , p. 35). Reafirmando: para Maturana (2001), no caminho da realidade objetiva, concebe-se a existência de uma realidade que independe do observador. A essa realidade, com existência própria, ele, o observador, tem um acesso privilegiado que sustenta sua elaboração explicativa, sob forma de concepções, definições e teorias, que configuram afirmações cognitivas como petições de obediência. Uma violência epistemológica, por negligenciar as coerências operacionais, a presença e as experiências do e como observador. Não tenho permissão para reformular minhas experiências com elementos de minhas experiências. Explicar, com base objetiva, é considerar a existência da realidade em si, independente do observador, uma realidade última, completa, pronta e acabada, cuja referência ocorre "a partir do domínio das ontologias transcendentes." (MATURANA, 2001, p. 42).

Também na dimensão da realidade objetiva é fonte de violência a pretensão de universalidade, como escreve Maturana (2001, p. 52):

o problema das pretensões de universalidade está em crer que se faz referência a uma realidade independente do

\footnotetext{
14 Citamos como exemplo o etnocentrismo, que segundo Rocha (1988, p. 7), "é uma visão do mundo onde o nosso próprio grupo é tomado como centro de tudo e todos os outros são pensados e sentidos através dos nossos valores, nossos modelos, nossas definições do que é a existência. No plano intelectual, pode ser isto como a dificuldade de pensarmos a diferença; no plano afetivo, como sentimentos de estranheza, medo, hostilidade, etc."
} 
observador, sem se dar conta de que a universalidade fica definida pelos critérios de constituição do sistema racional que se propõe. Se eu pretendo fazer referência a uma realidade independente, tenho a universalidade que supostamente essa realidade independente me dá. E aí, o que eu digo é válido para todos os seres humanos em qualquer circunstância. Porque é objetiva.

○tirano, o negador do outro, aquele que deseja que o outro obedeça, encontra guarida para suas atitudes, nessas afirmações universais, ou em suas atitudes e subjetividade tornadas universais por autoritarismo. ${ }^{15}$

No caminho da objetividade entre parênteses, ou das "ontologias constitutivas", "[...] tudo o que é dito é dito por um observador a outro observador que pode ser ele ou ela mesma." (MATURANA, 2001, p. 37). E, sendo a realidade um argumento explicativo, a explicação não é uma forma diferente de referenciar, ou uma visão diferente da mesma realidade, mas indica que existem "tantas realidades - todas diferentes, mas igualmente legítimas quantos domínios de coerências operacionais explicativas, quantos modos de reformular a experiência, quantos domínios cognitivos pudermos trazer à mão." (MATURANA 2001, p. 38). Então, o que vem à tona são experiência de vida e compreensões.

A realidade objetiva sem parênteses é marcada pela presença de uma epistemologia que sustenta ser o conhecimento científico fruto da materialidade de um mundo existente de forma independente do observador. Essas teorias usam da força para afirmar que o conhecimento é racional e universal, o que leva à violência da negação do outro, à não aceitação das diferenças nas observações, à não aceitação das singularidades e das subjetividades. ${ }^{16}$ Trata-

15 Ilustramos esse universalismo fazendo referência a um escrito de Laraia (1986, p. 17): "são velhas e persistentes as teorias que atribuem capacidades específicas inatas a 'raças' ou a outros grupos humanos. Muita gente ainda acredita que os nórdicos são mais inteligentes do que os negros; que os alemães têm mais habilidades para a mecânica; que os judeus são avarentos e negociantes; que os norte-americanos são empreendedores e interesseiros; que os portugueses são muito trabalhadores e pouco inteligentes; que os japoneses são trabalhadores, traiçoeiros e cruéis; que os ciganos são nômades por instinto, e, finalmente, que os brasileiros herdaram a preguiça dos negros, imprevidência dos índios e a luxúria dos portugueses."

16 Criamos estereótipos, preconceitos e rotulamos grupos de pessoas, como descreve Rocha (1988, p. 20): "Rotulamos e aplicamos estereótipos através dos quais nos guiamos para o confronto cotidiano com a diferença. As idéias etnocêntricas que temos sobre 'mulheres', os 'negros', os 'empregados', os 'paraíbas de obra', os 'colunáveis', os 'doidões', os 'surfistas', as 'dondocas', os 'velhos', os 'caretas', os 'vagabundos', os 'gays' e todos os demais 'outros' com os quais temos fami- 
se de um conhecimento científico que hierarquiza o acesso ao conhecimento e, portanto, de uma epistemologia fechada num raciocínio lógico.

Na contramão dessa lógica, faz sentido o dizer de Einstein (apud MATURANA, 2001, p. 58): "as teorias científicas são criações livres do espírito humano." Como criações do espírito humano, e não dados da realidade pronta, pode-se levar em conta os casos particulares enquanto fenômenos para os quais a teoria tem que servir (MATURANA, 2001, p. 65). Como criações do espírito humano, um ser finito, não cabe mais falar da violência como um dado estatístico, uma coisa mensurável, um algo a ser determinado empiricamente e compreendido de modo unívoco e totalizante de seus múltiplos aspectos fenomênicos, representacionais e significativos. Nesse contexto, para além do âmbito das experiências e das relações, importa o tipo de relação em que o espírito fora forjado e em que tipo de relações se encontra como ser-aí. A consciência da complexidade humana, uma condição humana que também emerge das violências, não será de imediata compreensão. Ela requer um paciente trabalho de interpretação, um empenho naquilo que Paul Ricoeur (1978) chamou de "a via longa da compreensão" em sua dinâmica travessia semântica.

Considerando ser paradoxal toda e qualquer ideia de violência, Maffesoli (1987, p. 9) afirma que a violência "é uma forma envolvente que tem suas modulações paroxístas e suas manifestações minúsculas", ou seja, um mistério indizível "que nos obscurece, que ocupa nossa vida e nossas discussões, que perturba nossas paixões e razões." Assim, e, conforme Zizek (2014), o testemunho de uma vítima da violência torna-se verídico diante da incoerência factual, da descrição confusa e informal. Nas palavras do autor: "As deficiências factuais do relato do sujeito traumatizado quanto a sua experiência confirmam a veracidade do testemunho, uma vez que indicam que o conteúdo descrito 'contaminou' o modo de sua descrição." (ZIZEK, 2014, p. 19).

Violência como mistério indizível, ainda assim, exigente do exercício de precisão e de pureza terminológica ao alicerçar sempre reflexões e concepções, como entende Arendt (1985).

liaridade, são uma espécie de 'conhecimento', um 'saber', baseado em formulações ideológicas, que no fundo transforma a diferença pura e simples num juízo de valor perigosamente etnocêntrico." 
Segundo a autora, a violência é também um instrumento utilizado pelo ser humano para seus projetos de dominação. Ela fez séria crítica à violência dos grupos de esquerda, apesar de seus projetos de transformação social, e afirma que, no fundo, tanto os teóricos políticos da esquerda quanto da direita concordam com a utilização da violência na luta pelo poder. Nas palavras da autora:

Se nos voltarmos para os debates sobre o fenômeno do poder, descobriremos logo que existe um consenso entre os teóricos políticos da esquerda e da direita de que a violência nada mais é do que a mais flagrante manifestação de poder. Toda política é uma luta pelo poder; o tipo de poder mais definitivo é a violência. (HANNA, 1985, p. 22).

Arendt é contundente em sua crítica, pois a busca de poder por intermédio da violência pode produzir dominação e, sem uma rigorosa disciplina linguística na definição dos termos e dos conceitos, não seria possível avançar dinamicamente para qualquer plano teórico ou conceptual minimamente estruturado, coerente e autossustentável.

Mesmo que precário e inseguro, consideramos relevante sinalizar algumas necessárias superações. Iniciamos com o alerta de Agamben ao referir-se à violência epistemológica que elimina o observar do observador, que elimina as subjetividades e as diferenças na observação, por terem implicações na potência e impotência. Agamben (2010) em "sobre o que podemos não fazer" e apoiado na Metafísica de Aristóteles, enuncia a potência de não ser, de não fazer, como a "potência da inoperosidade". O autor escreve:

Deleuze definiu uma vez a operação do poder como um separar os homens daquilo que podem, isto é, da sua potência. As forças ativas são impedidas no seu exercício ou porque são privadas das condições materiais que o tornam possível, ou porque uma proibição torna esse exercício formalmente impossível. Nos dois casos o poder - e é esta a sua figura mais opressiva e brutal - separa os homens da sua potência e, desse modo, torna-os impotentes. Há, todavia, uma outra e mais dissimulada operação do poder, que não age imediatamente sobre o que os homens podem fazer - sobre a sua potência -, mas antes sobre a sua impotência, isto é, sobre o que não podem fazer ou, melhor, podem não fazer. (AGAMBEN, 2010, p. 58). 
Agamben lembra que a existência das instrumentalizações do poder político, social ou proveniente de epistemologias objetivas é possuidora de um perfil enganoso e dissimulado que não só age sobre o que seres humanos podem fazer, ou seja, sobre sua potência, mas sobre o que eles podem não fazer, sobre sua "potência de não", sobre seu "poder", a própria impotência. Escreve Agamben (2010, p. 58): "o homem é, por conseguinte, o ser vivo que, existindo sob o modo da potência, pode tanto uma coisa como o seu contrário, trate-se de fazer ou de não fazer." $\bigcirc$ autor certamente pretende reforçar uma significativa diferença entre "não poder fazer" e "poder não fazer", poder não exercitar a própria potência, mas como se efetiva este decidir fazer ou não fazer? Nas palavras de Agamben (2010, p. 58-59):

\begin{abstract}
É sobre esta outra face mais obscura da potência que hoje prefere agir o poder que se define ironicamente como "democrático". Separa os homens não só e não tanto daquilo que podem fazer, mas antes do mais e as mais das vezes daquilo que podem não fazer. Separado da sua impotência, privado da experiência do que pode não fazer, o homem de hoje crê-se capaz de tudo e repete o seu jovial "não há problema" e o seu irresponsável "pode fazer-se", precisamente quando deveria antes dar-se conta de ser entregue numa medida inaudita a forças e processos sobre os quais perdeu qualquer controle. Tornou-se cego não ao que pode fazer, mas ao que não pode ou pode não fazer [...] Nada rende tantos pobres e tão pouco livres como este estranhamento da impotência. Aquele que é separado do que pode fazer, pode, todavia, resistir ainda, pode ainda não fazer. Aquele que é separado da sua impotência perde em contrapartida, antes do mais, a capacidade de resistir. E como é somente a calcinante consciência do que não podemos ser a garantir a verdade do que somos, assim também é somente a visão lúcida do que não podemos ou podemos não fazer a dar consistência ao agir.
\end{abstract}

Essa temática é retomada por Agamben em A potência do pensamento, no qual escreve que "Ter uma potência, ter uma faculdade significa: ter uma privação" (AGAMBEN, 2015, p. 245) e que a potência é definida constitutivamente pela possibilidade de seu não exercício.

A violência impositiva de epistemologias objetivas, ao mesmo tempo em que eleva as impotências na operacionalidade participativa, priva o ser humano da experiência daquilo que pode não fazer. E, ao crer-se capaz de tudo, segue uma trajetória de Homo agnus, incapaz de reagir diante de forças 
e processos sobre os quais perdeu qualquer controle. É também uma violência do silenciamento, como reflete Castor Ruiz (2013), uma vez que toda e qualquer forma de violência impõe a falência ou silenciamento do discurso e do diálogo. Ela viola a interlocução porque já não existe nada para se dizer.

Silenciamentos presentes nos dispositivos disciplinares, impostos por instituições de controle ao assumirem a tarefa de vigiar, medir, controlar e punir qualquer expressão do conflito, seja ele da natureza que for. $\bigcirc$ panoptismo, como descreve Foucault (2002, p. 163), "[...] controla os menores movimentos num trabalho ininterrupto. Cada indivíduo é constantemente localizado e examinado."

Os danos causados às vítimas da violência, por epistemologias objetivas podem, segundo reflexões de Ruiz (2013), reforçar a injustiça contra a vítima, como violência. $\bigcirc$ autor sustenta que as vítimas acabam se naturalizando em razão da naturalização da violência. São violências não regidas pela lógica linear do tempo, suas marcas não se apagam e desaparecem com o passar do tempo e serão possíveis companheiras pela vida toda, moldando sentires e fazeres, moldando visões de mundo, visões de ser humano e visões de vida. São violências que contaminam as estruturas, as instituições e as pessoas com quem se envolvem. Ruiz (2013) denomina "potência mimética" essa violência que permanece latejante como potência ativa contaminante e autorreprodutora da violência. Assim, a violência da atualidade tem relação com a violência semeada nas lógicas dos racionalismos que transformam o Homo sapiens em Homo agnus, vidas nuas, seres humanos sem fala e incapazes de sua impotência, ou seja, privados da experiência do que podem não fazer.

Mais especificamente nas palavras de Ruiz (2013, p. 85):

A potência mimética da violência possui uma especial conotação, ela tende a reproduzir como normais as semelhanças da violência. Torna a conduta das pessoas e das instituições semelhantemente violentas. A mimese naturaliza o comportamento, neste caso violento, e o reproduz de forma inconsciente como algo normal. Ela normaliza a violência tornando-a um componente normal da vida social ou uma tática natural para o governo institucional. A mimese da violência replica sua semelhança nas atitudes e valores ao ponto de torná-los normais. $\bigcirc$ dispositivo mimético normalizador da violência lhe confere um caráter 
natural, induzindo a sua (re)produção como algo normal/ natural.

Essas lógicas que normalizam e naturalizam as violências encontram guarida nas epistemologias reprodutivistas, com seu teor de neutralidade, com sua obstinação pela existência de uma realidade única, ignorando o observador, ignorando a linguagem como construtora de realidades. É preciso persistir nas lógicas da negação participativa e observadora, é preciso insistir no esquecimento, pois, conforme Ruiz (2013), a negação e o esquecimento tornam-se condições necessárias para a reprodução mimética da violência. Dessa forma, políticas de esquecimento não neutralizam somente o potencial mimético da violência, mas cometem uma outra injustiça contra as vítimas, apagando sua história e apagando-as da história.

Também Boaventura de Souza Santos contribui quando acena para a necessidade de superar os epistemicídeos. Para Santos (2010, p. 87), as epistemologias transformadas em "epistemicídios" são formas de violência que assassinam conhecimentos não hegemônicos, uma vez que "[...] as trocas desiguais entre culturas têm sempre acarretado a morte do conhecimento próprio da cultura subordinada e, portanto, dos grupos sociais seus titulares." $\bigcirc$ "[...] exclusivismo epistemológico da ciência moderna [...]" (SANTOS, 2010, p. 26) foi uma condição da expansão da Modernidade europeia, evidenciando relações coloniais, assumindo aspectos totalitários e negando o caráter racional a todas as outras formas de conhecimento.

Na trilha íngreme de alternativas nos inspiramos em Morin e Viveret (2015), particularmente em seu convite para uma mudança de visão. Mas se a violência está na ordem do dia, se a violência emerge das sombras do individual e do social para tornar-se mais uma vez um fenômeno real, visível fisicamente ou mesmo subliminarmente dissimulada junto às regras e aos dispositivos, em sendo a violência, mais uma vez considerada como falha, como erro, como transgressão, ela também instaura uma diferente ordem, porque desequilibra normativos anteriores e cristalizados para impor a reorganização, para promover a união de contrários que, paradoxalmente passam a ser concorrentes e complementares (MORIN; VIVERET, 2015). Na ânsia de extinguir do Planeta a violência que incomoda, desorganiza, assusta e vem ceifando 
vidas, horrorizando com a presença, em si, da monstruosidade, do ainda não entendido, da frustração do não sucesso no combate, da arrogância da presença em todos os lugares, da imprevisibilidade quanto a seu surgimento, estratégias contra ela são elaboradas e levadas a cabo, então é preciso reconhecer na violência sua fonte real, sua origem. Sem raiz cortada, ela pode novamente e sempre brotar, para desgosto de todos nós; há, pois, uma situação incômoda e uma reflexão profunda por fazer. Urge repensar o que subjaz às nossas estruturas de pensamento, uma vez que é importante mudar o olhar... UMA OUTRA SENSIBILIDADE (MORIN; VIVERET, 2015).

Indicamos uma outra trilha apoiada em Agamben e seu convite para a profanação. Se a trajetória humana, em seu processo civilizador, vestiu-se de violência, se a contemporaneidade se recobre com a aura da necessidade e do inevitável, uma espécie de sagrado, Agamben sonha e aposta na possibilidade de descriar esse consolidado existente. $\bigcirc$ exercício da potência e da impotência é, nas reflexões de Agamben, mais do que um acomodar-se ao status quo. O autor se refere ao escriturário Bartley de Melville que, podendo o que pode, podendo a sua potência de ser, prefere exercer a sua impotência, não ser, "prefere não" escrever (AGAMBEN, 2013).

De acordo com Agamben (2015),

[...] devemos ainda medir todas as consequências dessa figura da potência que, ao se doar a si mesma, se salva e cresce no ato. Ela obriga-nos a repensar na sua totalidade não apenas a relação entre potência e ato, entre o possível e o real, mas de considerar de modo novo, na estética, o estatuto do ato de criação da obra e, na política, o problema da constituição do poder constituinte no poder constituído. É, porém, toda a constituição do ser vivo que deve ser posta em xeque se for verdade que a vida deve ser pensada como potência que incessantemente excede as suas formas e as suas realizações.

Compreender a violência, reconhecer a nossa inevitável decadência, negligência, ausência e omissão, bem como reconhecer a presença muitas vezes da violência como providencial, nos injustificáveis atos de imprudência e nas intolerâncias à alteridade, tenhamos a potência para combater a violência 
e exercitemos a impotência de "não preferir" ações violentas - "potência de ser e de não ser".

Mas como transcender a violência, como superar o poder soberano, e, juntamente com essas superações, a vida nua, para reabrir a dimensão da biós (vida qualificada) para cada um e todos os seres humanos? Para Agamben, a resposta é: profanando todas as coisas, no sentido de torná-las de uso comum. Conforme o autor:

Puro, profano, livre dos nomes sagrados, é o que é restituído ao uso comum dos homens. Mas o uso aqui não aparece como algo natural; aliás, só se tem acesso ao mesmo através de uma profanação. Entre "usar" e "profanar" parece haver uma relação especial, que é importante esclarecer. (AGAMBEN, 2007, p. 65).

Para o exercício da impotência, "preferir a não violência", o ser humano deve profanar, tornar comum o que está apropriado, tornar de uso comum o que está sob o domínio, substituindo o domínio pelo livre uso. Para Agamben (2007, p. 65), o conceito de profanação é concebido em oposição ao de sacralização. Escreve o autor: "se consagrar (sacrare) era o termo que designava a saída das coisas da esfera do direito humano, profanar, por sua vez, significava restituí-las ao livre uso dos homens", ou seja, restituir ao livre uso da comunidade humana aquilo que lhe foi tirado pela consagração seria o mesmo gesto de retomar para o uso comum aquilo que epistemologias da violência, ou dispositivos sequestraram, para um diferente uso, considerado adequado. Por isso, "Profanar não significa simplesmente abolir e cancelar as separações, mas aprender a fazer delas um uso novo, a brincar com elas." (AGAMBEN, 2007, p. 75).

A comunidade humana, ao negligenciar as normas constituídas e mantidas pelos dispositivos, via epistemologias da desigualdade, possibilita a revolução que não se limita e nem significa fazer um uso adequado dos dispositivos, permite a ruptura com o próprio dispositivo - epistemologias e sua transformação em uma nova realidade. Profanar significa aprender a fazer "um uso novo", assim, escreve Agamben (2007, p. 75), "A sociedade sem 
classes não é uma sociedade que aboliu e perdeu toda memória das diferenças de classe, mas uma sociedade que soube desativar seus dispositivos, a fim de tornar possível um novo uso, para transformá-las em meios puros." "Profanar o improfanável", como o racionalismo da tecnociência, o consumismo solitário, o silêncio da intimidade inconfessável, os dispositivos do biopoder e da biopolítica, a desigualdade, a violência da solidão e da dessubjetivação, as epistemologias das violências, é, como escreve Agamben (2007, p. 79), “[...] tarefa política da geração que vem."

Nessa geração que vem, "[...] o ser que vem é o ser qualquer [...]", um ser liberto das propriedades universais bem como das bases de indivíduo, por ser "[...] o ser, tal que, seja qual seja, importa", não é um universal nem um indivíduo enquanto incluído numa série, mas "a singularidade enquanto singularidade qualquer." (AGAMBEN, 2013, p. 9).

É essa geração que vem, um ser qualquer, numa comunidade que vem, não uma comunidade como propriedade de seus membros, com um valor supremo a preservar, mas uma comunidade que, não tendo uma essência, nem sendo um valor supremo, se realiza não na busca de algo que lhe é próprio, mas, ao contrário, na sua impropriedade.

Nessa comunidade que vem,

[...] todo o discurso sobre a ética é que o homem não é, nem há de ser ou realizar nenhuma essência, nenhuma vocação histórica ou espiritual, nenhum destino biológico. Apenas por isso deve existir algo assim como uma ética: pois está claro que se o homem fosse ou tivesse que ser esta ou aquela substância, este ou aquele destino, não existiria experiência ética possível, e apenas tarefas a realizar. (AGAMBEN, 2013, p. 45).

Esse ser qualquer será um "sujeito" ético, despido de sua essência, não prisioneiro de uma unidade, mas a ser entregue verdadeiramente à dimensão da alteridade, emergindo em relações. E no contexto efetivo da alteridade a política terá um fato novo: a "política que vem é que ela não será já a luta pela conquista ou controle do Estado, mas luta entre o Estado e o não Estado (a 
humanidade), disjunção irremediável entre as singularidades quaisquer e a organização estatal." (AGAMBEN, 2013, p. 78).

Profanar as epistemologias que fizeram e fazem pervagar as violências dos mais diversos matizes e amplitudes, para restaurar um ser humano qualquer, sem essência ou destino a galgar, numa comunidade que vem, ensonhando a humanidade, vacilante entre a singularidade e o universal, uma dissociação de sua precária existência, que impõe o silêncio, é uma tarefa da formação que vem. Ainda assim: Como poder vir esse qualquer sem que seja violência ou expressão da violência? Quais experiências formativas possibilitam a emergência do qualquer que pode a não violência?

\section{REFERÊNCIAS}

A GLOBALIZAÇÃO da indiferença nos tirou a capacidade de chorar. $\bigcirc$ discurso de Francisco em Lampedusa. Institutos Humanitas Unisinos, 09 jul. 2013. Disponível em: <http://www.ihu.unisinos.br/noticias/521786-qadao-onde-estas-caim-onde-esta-o-teu-irmao-o-discurso-de-francisco-em-lampedusa >. Acesso em: 09 ago. 2013.

AGAMBEN, G. A comunidade que vem. Belo Horizonte: Autêntica, 2013.

AGAMBEN, G. A potência do pensamento ensaios e conferências. Belo Horizonte: Autêntica, 2015.

AGAMBEN, G. Homo Sacer. Belo Horizonte: Ed. UFMG, 2002.

AGAMBEN, G. Nudez. Portugal/Lisboa: Relógio D’Água Editores, 2010.

AGAMBEN, G. Profanações. São Paulo: Boitempo, 2007.

AGOSTINI, N. O mal nos desafia. Perspectiva Teológica, Belo Horizonte: $\bigcirc$ Lutador, ano 33, n. 91, set./dez. 2001.

ANTUNES, R. (Org.). Riqueza e Miséria do Trabalho no Brasil. São Paulo: Boitempo, 2006.

ANTUNES, R. (Org.). Riqueza e Miséria no Trabalho no Brasil 2. São Paulo: Boitempo, 2013.

ANTUNES, R. (Org.). Riqueza e Miséria do Trabalho no Brasil III. São Paulo: Boitempo, 2014. 
ARENDT, H. Da violência. Brasília, DF: Ed. da Universidade de Brasília, 1985.

ASSMANN, H. Metáforas novas para reencantar a educação: epistemologia e didática. Piracicaba: Ed. Unimep, 2011.

BAUMANN, Z. O mal-estar da pós-modernidade. Rio de Janeiro: Jorge Zahar Editor, 1998.

BENJAMIN, W. Escritos sobre mito e linguagem: para uma crítica da violência (1915-1921). São Paulo: Duas Cidades; Editora 34, 2011.

BENJAMIN, W. Sobre o conceito de história. In: LOWY, M. (Org.). Walter Benjamin: aviso de incêndio: uma leitura das teses "Sobre o conceito de história". São Paulo: Boitempo, 2005.

DADOUN, R. A violência: ensaio acerca do "homo violens". Rio de Janeiro: DIFEL, 1998.

DELEUSE, G.; GUATTARI, G. Mil platôs: capitalismo e esquizofrenia, V. I. Rio de Janeiro: Editora 34, 1995.

DRAWIN, C. R. O paradoxo antropológico da violência In: ROSÁRIO, Â. B.; NETO, F. K.; MOREIRA, J. O. (Org.). Faces da violência na contemporaneidade: sociedade e clínica. Barbacena, Minas Gerais: Ed. UEMG, 2011.

ELIAS, N. O processo civilizador. Rio de Janeiro: Jorge Zahar Editor, 1993. v. l e 2 .

FOUCAULT, M. História da sexualidade I: a vontade de saber. Rio de Janeiro: Graal, 1988.

FOUCAULT, M. Vigiar e punir. 26. ed. Petrópolis: Vozes, 2002.

HEIDEGGER, M. Sobre o humanismo. Rio de Janeiro: Edições Tempo Brasileiro, 1995.

LARAIA, R. B. Cultura: um conceito antropológico. 14. ed. Rio de Janeiro: Jorge Zahar Editor, 1986.

LOBACZEWSKI, A. Ponerologia: psicopatas no poder. Campinas: Vide Editorial, 2006.

$\mathrm{MACHADO}$, J. P. Dicionário Etimológico da Língua Portuguesa - 5 Volumes. 12. ed. Lisboa: Livros Horizonte, 2003. 
MAFFESOLI, M. Dinâmica da violência. São Paulo: Revista dos Tribunais, 1987.

MATURANA, H. Cognição, ciência e vida cotidiana. Belo Horizonte: Ed. UFMG, 2001.

MATURANA, H. Da biologia à psicologia. 3. ed. Porto Alegre: Artes Médicas, 1998.

MORIN, E. Ciência com consciência. 13. ed. Rio de Janeiro: Bertrand, 2010.

MORIN, E. O Método 5: A Humanidade da Humanidade, a identidade humana. 2. ed. Porto Alegre: Sulina, 2003.

MORIN, E.; VIVERET, P. Como viver em tempo de crise? 2. ed. Rio de Janeiro: Bertrand Brasil, 2015.

PEREIRA, C. A. M. et al. Linguagens da violência. Rio de Janeiro: Rocco, 2000.

QUEIRUGA, A. T. Do terror de Isaac ao abbá de Jesus. São Paulo: Paulinas, 2001.

RICOEUR, P. Existência e hermenêutica. In: RICOEUR, P. (Org.). O conflito das interpretações: ensaios de hermenêutica. Rio de Janeiro: Imago, 1978.

ROCHA, E. P. G. O que é etnocentrismo. 5. ed. São Paulo: Brasiliense, 1988.

ROCHA, Z. Paixão, violência e solidão: o drama de Abelardo e Heloísa no contexto cultural do século XII. Recife: Ed. UFPE, 1996.

RUIZ, B. C. Genealogia da biopolítica. Legitimações naturalistas e filosofia crítica. Revista do Instituto Humanitas Unisinos, Porto Alegre: Unisinos, n. 386, 2012 .

RUIZ, B. C. (In)justiça, violência e memória: o que se oculta pelo esquecimento, tornará a repetir-se pela impunidade. In: SILVA FILHO, J. C. M.; ABRÃO, P.; TORELLY, M. D. (Org.). Justiça de transição nas Américas: olhares interdisciplinares, fundamentos e padrões de efetivação. Belo Horizonte: Fórum, 2013.

SANTOS, B. S. A Gramática do Tempo. 3. ed. São Paulo: Cortez, 2010. 
SANTOS, M. F. dos. Teoria do Conhecimento (Gnosiologia e Criteriologia). São Paulo: Logos, 1960.

TOURAINE, A. Crítica da Modernidade. 7. ed. Petrópolis: Vozes, 2002.

WATSLAWICK, P. A realidade inventada, como sabemos o que cremos saber. Campinas: Psy, 1994.

ZILLES, U. Teoria do conhecimento e teoria da ciência. 2. ed. São Paulo: Paulus, 2008.

ZIZEK, S. Violência. São Paulo: Boitempo, 2014.

Recebido em:: 29 de setembro de 2017 Aceito em:: 04 de maio de 2018

Endereço para correspondência: Rua Getúlio Vargas, 2125, Flor da Serra, Joaçaba, Santa Catarina, Brasil; roque.strieder@unoesc.edu.br 